\title{
ATELLIÊE
}

\section{Materialização, substrução e projeção: uma construção teórico-metodológica como contribuição para o desvelar da produção do espaço}

\author{
Materialización, substrucción y proyección: una \\ construcción teórico-metodológica como contribución para \\ el desvelar de la producción del espacio
}

\begin{abstract}
Materialization, substruction and projection: a theoreticalmethodological construction as a contribution to unveiling the production of space
\end{abstract}

\author{
Alvaro Ferreira \\ Pontifícia Universidade Católica do Rio de Janeiro \\ Universidade do Estado do Rio de Janeiro \\ alvaro_ferreira@puc-rio.br
}

\begin{abstract}
Resumo
A Geografia tem passado por momentos de negação da importância do debate teórico. Por outro lado, há autores que insistem em não se preocupar com a dimensão empírica; há equívocos nas duas partes. Acreditamos que o ponto de partida da investigação deve ser a realidade, mas posteriormente é necessário retomar a dimensão teórica para tentar desvendar o problema. A reflexão realizada neste texto foi construída a partir de uma base metodológica baseada na tríade dos processos de materialização, substrução e projeção.
\end{abstract}

Palavras-chave: Produção do espaço, base metodológica, tríade materializaçãosubstrução-projeção

\section{Resumen}

La Geografía ha pasado por momentos de negación de la importancia del debate teórico. Por otro lado, hay autores que insisten en no preocuparse por la dimensión empírica; hay equívocos en las dos partes. Creemos que el punto de partida de la investigación debe ser la realidad, pero posteriormente es necesario retomar la dimensión teórica para intentar desvelar el problema. La reflexión realizada en este breve texto fue construida a partir de una base metodológica basada en la tríada de los procesos de materialización, substrucción y proyección.

Palabras clave: Produccíon del espacio, base metodológica, tríada materializaciónsubstrucción-proyección 


\begin{abstract}
Geography has gone through moments of denial of the importance of theoretical debate. Still there are authors who insist not worrying about the empirical dimension; there are misunderstandings in both parts. We believe that reality must be the starting point of the investigation, but it is also important to return to the theoretical dimension afterwards to unveil the problem. The reflection made in this brief text was constructed from a methodological basis composed by the triad of materialization, substruction and projection processes.

Keywords: Production of space, methodological basis, triad materializationsubstruction-projection
\end{abstract}

\title{
Introdução... ou apresentando um problema
}

A ciência geográfica, ou melhor, os geógrafos, desde muito tempo, enfrentam intensos debates, internamente à própria ciência, quando se veem questionados quanto ao aporte teórico-metodológico da Geografia. Isso é agravado por seu caráter particular, em outras palavras, pelo que conhecemos como Geografia Física e por Geografia Humana, pois além das diferenças no que se refere ao método científico - ao método de abordagem -, há também grande diferença em relação aos procedimentos de investigação (procedimentos de pesquisa), ou como alguns preferem, ao procedimento e método. Embora não seja o objetivo deste artigo, importa dizer que a confusão que muitas vezes se faz entre método científico e procedimentos de pesquisa, é também muito negativo para o desenvolvimento da ciência.

Além de toda a dificuldade elencada anteriormente, vivenciamos um momento de forte abandono da construção teórica. Há um forte discurso de parte da academia - e isso se reflete nos pós-graduandos - de que o que importa é ser propositivo; parece-me equivocada tal simplificação. Por outro lado, há grupos que acreditam ser necessário continuar trabalhando apenas dentro do horizonte analítico e da construção teórica. Vemos exageros nas duas posições.

É preciso entender que a construção teórico-metodológica deve servir para revelar aquilo que está por trás do que se apresenta. E mais, é preciso compreender para transformar, diria Karl Marx. Ou seja, é preciso passar da interpretação do real para a sua crítica e transformação (LÖWY, 2012). Assim, não devemos separar a dimensão da ação social da dimensão da ciência. E nesse sentido, não devemos esquecer de que importa interpretar o mundo, mas com o objetivo de contribuir para transformá-lo. E aqui não se trata de substituir os movimentos sociais, mas de ajuda-los na construção do "movimento autônomo da imensa maioria em proveito da imensa maioria" (Marx, Engels, 1998, p.19). 


\section{Materialização, substrução e projeção: proposta de método de investigação}

Ao contrário do que temos visto em vários artigos científicos, que dão grande ênfase à discussão teórica muitas vezes desprendida do real, reafirmamos que o ponto de partida tem que ser o real. Após a identificação do problema em questão, daquilo que nos inquieta, é que devemos voltar-nos à teoria, mas sempre preocupados com o movimento entre prática e teoria. Através da dialética é possível aliarmos a contraditória relação que mantém unida teoria e prática. Essa relação contribui para manter em aberto as contradições do processo social e histórico - que agrega as práticas e o imaginário, o concreto e o simbólico -, colaborando, assim, para evitar reducionismos deterministas e idealizações afastadas do real, ambas contribuindo para o fechamento do movimento e do diálogo crítico, quando o que buscamos é a abertura. Lembra-nos o geógrafo Leonardo Brasil Bueno (2008, p. 14) que é preciso "evitar os riscos opostos e complementares. (...) De um lado, a aceitação não mediada e não criticada dos dados e fatos brutos da empiria fetichiza a suposta objetividade dos fatos, dos números e das estatísticas, como positividades que se autoexplicariam"; e de outro lado, "a teoria como exercício conceitual abstrato, de todo desligado da empiria, dos fatos e dos dados, das fontes e dos processos reais de trabalho, fazendo com que a pesquisa se esvazie e perca em rigor científico e conceitual".

Isso nos obriga a lidar com o fato de as questões teóricas mostrarem- se, inclusive, como problemas práticos. Assim, se acreditamos que o ponto de partida deve ser a realidade, isso também significa considerá-la como um limite à ação. Aliás, a própria teoria pode tornar-se um limite à transformação. É preciso entender que qualquer contraposição ao modelo vigente somente poderá partir de dentro do próprio capitalismo.

A reflexão realizada neste breve texto será construída a partir de uma base metodológica que apresentamos pela primeira vez em 2017 e está baseada na tríade dos processos de materialização, substrução e projeção (FERREIRA, 2017).

Ao debruçar-nos sobre o "real", vemo-nos diante de algo para além do concreto e de sua referida concretude. Assim, aquilo que se apresenta inicialmente está ligado ao perceptível, àquilo que pode ser captado pelos sentidos; ou seja, refere-se à materialização, que se encontra ligada à aparência, àquilo que se apresenta. Nesta fase o pesquisador irá descrever e analisar as formas, o espaço produzido.

Entretanto, há elementos que são anteriores ou que estão por trás da concretude observada, mas que são importantes para compreendermos a sua concreção. Referimonos a uma espécie de substrato que dá suporte a algo, que serve de base a um fenômeno. A esse processo podemos denominar substrução. Trata-se, nesse momento, de investigar os elementos anteriores ou que estão por trás da concretude, aquilo que lhe serve de sustentação. Tratam-se também de representações e de jogos de poder, que trazem consigo forças escusas, que trabalham para manterem-se ocultas. Este momento da análise promove uma reflexão acerca dos grupos sociais envolvidos no processo de 
produção, suas ações, reações e interações (parcerias entre Estado e Capital materializadas, por exemplo, em projetos de revitalização; mobilizações sociais etc. ${ }^{1}$ ).

Embora esse enorme jogo de forças, por vezes, encontre-se oculto, noutras vezes, o que se mostra são as representações, que contêm por excelência interditos, interesses escusos, falsidades, poderes ocultos, ambiguidades... As representações são muito importantes para compreendermos o processo de substrução; aliás, quanto a elas, o filósofo francês Henri Lefebvre (2006, p. 58) afirmou que são falsas no que apontam e dizem (porque dissimulam objetivos reais), mas são verdadeiras quanto ao que sustentam. Isso nos obriga a ter em conta que temos a dimensão da apresentação e da representação, de que há a aparência e o que está oculto na aparência.

Em sendo o espaço um produto social, podemos afirmar que por trás de sua produção há intencionalidades. A conjugação de substrução e materialização tem nesse jogo um terceiro elemento: a projeção, que se refere à ideia de realização no futuro. Esse processo mira o futuro, mas o que determina o projeto é o passado e o presente vividos. Além disso, é preciso ter em conta que é pensado e levado a cabo a partir de uma construção ideológica, e que para tal, muitas vezes, faz uso de manipulações; até porque a definição do projeto também traz em si um jogo de poder. A projeção caracteriza-se como base para idealização de projetos de mundo, que podem ser reacionários, progressistas ou efetivamente revolucionários.

A projeção liga-se diretamente ao ato de projetar, e em geral, a substrução faz uso de artifícios ligados à mídia e à construção ideológica. Por isso, a relação entre um objeto e a construção de sua imagem (símbolo) é transformada, já que o produto é que passa a representar a imagem e não o contrário. Vivemos um momento em que a imagem e as representações ganham uma dimensão cada vez maior, em que verdadeiramente não é o consumidor ou a mercadoria consumida o que importa, mas sim a representação do consumidor e do próprio ato de consumir. Tudo isso é amplificado se tivermos em conta que tanto as mercadorias quanto o ato de consumir ganham formas e sentidos de espetacularização. Definitivamente, é por isso que, atualmente, prefiro falar em mercadificação em lugar de mercantilização, sendo que a primeira incorpora a segunda, mas vai além. Assim, ao falarmos de mercadificação do espaço (há autores que usam mercadorização), temos em conta agora, mais do que em qualquer momento anterior, a relação entre determinado espaço e sua imagem construída é modificada. É o espaço, transformado em produto, que passa a representar a imagem, e não o contrário. O que estamos querendo deixar claro é que, cada vez mais, o espaço é consumido pelo que ele representa; ou seja, o que representa frequentar e estar em determinado lugar. Em outras palavras, falar em mercadificação do espaço significa dizer que ele é mercantilizado, mas que essa mercadoria que estamos comprando é cada vez mais um estilo de vida, uma experiência cotidiana diferenciada, compramos o que representa ter aquilo, fazer parte daquele nicho (FERREIRA, 2017).

\footnotetext{
${ }^{1}$ Para encontrar uma discussão mais aprofundada acerca desse tema ver Ferreira, 2013b.
} 
A materialização nos permite, a partir do momento atual, observar, descrever e analisar as formas, o espaço produzido. Aqui importa também estarmos atentos para o fato de que a produção simbólica se encontra ligada à produção da vida material e às relações de produção. O uso do espaço, a vida que se dá no âmbito do lugar, as tensões entre apropriação e dominação, tudo isso também se encontra nessa dimensão analítica.

A substrução nos autoriza a reflexão acerca dos grupos sociais envolvidos no processo de produção, suas ações, reações e interações, pois o espaço é um produto social, modelado e condicionado a intencionalidades, racionalidades. Aqui, como dissemos anteriormente, estarão presentes relações de poder, ideologias, representações. Associações entre Estado e Capital (materializadas, por exemplo, em parcerias públicoprivadas, em projetos de revitalização ou grandes reformas urbanas), mobilizações sociais em contraposição às políticas estabelecidas, tudo isso é parte desta dimensão analítica. A análise da substrução trará luz àquilo que deu condições para a concretização da realidade atual. Em outras palavras, ajudará a esclarecer o que precedeu e deu suporte a situação atual, ao objeto a ser analisado.

A projeção mira o futuro, mas evidentemente o que determina o projeto é a história construída no passado e o presente vivido. Os projetos, que podem ser revolucionários ou que objetivem manter o status quo, são pensados, idealizados pelos grupos sociais que se encontram em tensão. O jogo de forças não é homogêneo e os artifícios usados são variados. A utilização da mídia, da racionalidade ligada à sociedade do consumo, os projetos idealizados pelos movimentos sociais em contraposição às políticas estabelecidas, tudo isso é parte desta dimensão analítica.

Convêm lembrar, ainda, que no momento em que estamos trabalhando com a materialização, descrevendo e analisando as formas produzidas, devemos considerar que elas são o resultado de um processo de projeção. Ou seja, materialização, substrução e projeção são totalmente imbricados e interdependentes, além de coexistirem no presente, passado e no projeto de futuro.

Quando, anteriormente, mencionamos a construção ideológica, temos de ter em conta que a ideologia pode ser pensada a partir de uma atitude contemplativa que não reconhece a sua intrínseca dependência em relação à realidade social, mas também a partir de um conjunto de crenças voltado à ação. Além disso, pode tratar-se, do mesmo modo, de uma construção de ideias falsas, crenças e conceitos que legitimam um poder político dominante. Evidentemente, quando um processo é denunciado como ideológico, podemos ter certeza de que por trás daqueles que denunciam há também um discurso ideológico. Atualmente, cada vez mais mercado e mídia de massa estão interligados; vivemos em uma "sociedade do espetáculo" (DEBORD, 1997) em que a mídia estrutura antecipadamente nossa percepção da realidade e a mistura à sua própria representação. 


\section{Aproximações a Henri Lefebvre}

Certamente é possível associarmos esse debate a algo desenvolvido por Lefebvre $(1974,2008)$ e que trata da associação entre representações e espaço. Fala-nos da produção de um espaço de representações que traz em si objetos concretos, mas também projetos e trajetos. Este espaço de ações (que podem estar em curso ou que podem ser ainda virtuais) encontra-se, embora seja diferente, com as representações do espaço, que trazem consigo lógicas, técnicas e projetos muitas vezes definidos e postos em curso pelos grupos dominantes; é concebido e representado. A experimentação disso se dá no âmbito das práticas espaciais, que são as práticas sociais projetadas no espaço social (que é ao mesmo tempo físico, social e mental); é o espaço da experiência e percepção a partir do prático-sensível. Lefebvre (2006) pretende construir uma teoria que não venha a abolir as representações, mas que nos permita resistir àquelas que fascinam as massas, e também que nos permita escolher as representações que ajudem a explorar o possível... a mudança.

Para desenvolver sua teoria acerca do espaço, Lefebvre $(1974,1994,2008)$ faz uso de tríades analíticas, dentre as quais podemos mencionar: o percebido, o concebido e o vivido; o físico, o mental e o social; as práticas espaciais, as representações do espaço e os espaços de representação; e o espaço absoluto, o espaço abstrato e o espaço diferencial. Cada elemento de cada uma das tríades está presente nos outros elementos da própria tríade e nas demais. Tratam-se de momentos da análise. As tríades são construídas com o objetivo de analisar as diferentes dimensões do espaço, e são compostas por elementos que as constituem. Funcionam como uma espécie de lupa, que nos permitiria desvendar melhor cada dimensão analítica. A tríade percebido-concebidovivido focaria a dimensão da percepção através do corpo; da corporeidade. A tríade práticas espaciais-representações do espaço-espaços de representação tem como foco a espacialidade. As relações sociais são sempre espaciais e existem a partir da construção de certas espacialidades. Trata-se de considerar a espacialidade efetivamente vivida e socialmente criada; ou seja, a construção da espacialidade como um produto de processos sociais e rebatimentos materiais, ao mesmo tempo concreta e abstrata. Assim, estaremos percebendo-a como parte do espaço socialmente construído. Nesse sentido, não é possível ignorarmos as diversas lutas simbólicas travadas no espaço urbano, em que está em questão a própria representação de mundo (FERREIRA, 2013a, 2013b, 2014). E, finalmente, a tríade espaço absoluto-espaço abstrato-espaço diferencial traria à luz o tempo, a temporalidade em todas as suas contradições.

Ao considerar as representações como fatos da prática social, é possível compreender a consciência e o pensamento sem omitir o real; e é possível escapar da alienação (que, por vezes, se esconde por trás da substrução), orientando-nos em direção ao possível, correndo riscos... buscando, através da projeção, construir o objeto virtual, aproximando-nos do impossível; pois, como sabemos, para conseguirmos o possível, é necessário mirar o impossível. 


\section{Algumas considerações ou apenas tentando finalizar...}

Constituímo-nos, em nossa humanidade, das dimensões do ser mental, do ser físico e do ser social, que constituem uma unidade multidimensional. Cotidianamente, internalizamos regras, normas, instituições, valores e representações, que fazem parte de nossa existência social. Quando ouvimos falar em indivíduo, não devemos esquecer que ele se representa na dimensão social, já que somente se realiza concretamente no social. A dimensão social de representação de atores e agentes ${ }^{2}$ se dá no âmbito do lugar, e se revela através da materialização. Nesse sentido, as práticas espaciais definem lugares, que se revelam e se constituem através da relação entre o local e o global, que se realiza através de ações, reações e interações entre os diferentes atores e agentes na produção do espaço; além disso, definem a representação dessa relação, dessas ações e interações (aqui encontramo-nos no âmbito da substrução). Tudo isso acaba por constituir-se no cotidiano. É nele que vivenciamos a alienação, mas é também a partir dele que podemos lutar contra ela, insurgir-nos...

A cidade é para ser vivida em plenitude por todos os cidadãos, assim é necessário articular arte, cultura, comunicação e direcionamento político para realizar a verdadeira transformação do espaço urbano; em outras palavras, é necessário ultrapassar o momento atual - da cidade como produto, comercializável - e restituir o sentido da cidade enquanto obra, produzida no cotidiano pelas pessoas, pelas diferenças e não pela mercadoria. Ou seja, estaríamos caminhando para a retomada, pela sociedade, da definição de seu destino, para uma espécie de autogestão. Se, por um lado, os usuários do espaço urbano podem alienar-se pelas representações do espaço, como no projeto de mercadificação da cidade, na produção do espaço voltado ao turismo; por outro lado, podem se apropriar dela de outra maneira, a partir de uma miríade de possibilidades inclusive como espaço de reivindicações - e vivê-la como o lugar do encontro, da festa, das manifestações culturais espontâneas dos moradores; trata-se aqui de outro projeto, ou seja, estamos caminhando pelo processo de projeção. Entendemos assim porque Lefebvre (1994, p. 349) acreditava que a apropriação e o uso do espaço podem persistir nos espaços de representação, abrindo a possibilidade de pensarmos na construção de um espaço diferencial ${ }^{3}$, visto como resistência e como potencialidade, como "uma iniciativa utópica alternativa para o espaço existente atualmente".

Indicar o que é possível exige que se entre no terreno das opções políticas, mas importa não perder o compromisso com a esfera que ultrapassa as escolhas imediatas. A utopia envolve, simultaneamente, as limitadas escolhas do imediato e as possibilidades ilimitadas do futuro. Estamos mirando um impossível-possível.

\footnotetext{
${ }^{2}$ Em texto anterior (FERREIRA, 2013a), discuto e apresento a diferença entre as categorias sujeito, ator e agente.

${ }^{3}$ É possível relacionarmos esse debate à noção de heterotopia desenvolvida pelo filósofo francês Michel Foucault $(1986 ; 1981)$.
} 


\section{Referências}

BUENO, L. B. Forma e sentido da resistência na cidade do Rio de Janeiro: a luta da ocupação Quilombo das Guerreiras. 2008. 114f. Dissertação (Mestrado em Planejamento Urbano e Regional) - Instituto de Pesquisa e Planejamento Urbano e Regional, Universidade Federal do Rio de Janeiro, 2008.

DEBORD, G. A sociedade do espetáculo. Rio de Janeiro: Contraponto, 1997. 238p.

FERREIRA, A. Produção alienadora das cidades e indícios de insurgência: materialização, substrução e projeção. In.: FERREIRA, A; RUA, J; MATTOS, R. C. de. (Orgs.) O espaço e a metropolização: cotidiano e ação. Rio de Janeiro: Consequência, 2017, p. 91-120.

FERREIRA, A. Metropolização do espaço, tensões e resistências: entre espaços de controle e controle do espaço. Scripta Nova: Revista Electrónica de Geografía y Ciencias Sociales, Universidad de Barcelona, v. XVIII, n. 493 (55), 1 de nov. de 2014.

FERREIRA, A. A imagem virtual transformada em paisagem e o desejo de esconder as tensões no espaço: por que falar em atores, agentes e mobilizações? In: FERREIRA, A; RUA, J; MARAFON, G; SILVA, A. C. P. da (Orgs.). Metropolização do espaço: gestão territorial e relações urbano-rurais. Rio de Janeiro: Consequência, 2013a. p. 53-74.

FERREIRA, A. A cidade no século XXI: segregação e banalização do espaço. 2. ed. ampliada. Rio de Janeiro: Consequência, 2013b. 323p.

FOUCAULT, M. Of other spaces. Diacritics, n. 16, v. 1, p. 22-27, 1986.

FOUCAULT, M. As palavras e as coisas. Uma arqueologia das Ciências Humanas. São Paulo: Martins Fontes, 1981.

LEFEBVRE, H. Espaço e política. Belo Horizonte: UFMG, 2008.

LEFEBVRE, H. La presencia y la ausencia: contribución a la teoría de las representaciones. México: FCE, 2006. 305p.

LEFEBVRE, H. The production of space. Oxford, UK: Blackwell, 1994.

LEFEBVRE, H. La production de l'espace. Paris: Anthropos, 1974.

LÖWY, M. A teoria da revolução no jovem Marx. 1ed., ampl. e atual. São Paulo: Boitempo, 2012.

MARX, K; ENGELS, F. Manifesto do Partido Comunista. In: REIS FILHO, D. A (org.). O Manifesto Comunista 150 anos depois. Rio de Janeiro: Contraponto; São Paulo:

Perseu Abramo, 1998, p. 7-41. 


\begin{abstract}
Alvaro Ferreira
Possui pós-doutorado pela Universidad de Barcelona, doutorado em Geografia Humana pela USP, mestrado em Planejamento Urbano e Regional pelo IPPUR da Universidade Federal do Rio de Janeiro e graduação em Geografia Universidade do Estado do Rio de Janeiro. Atualmente é Professor Adjunto do Departamento de Geografia e do Programa de Pós-Graduação em Geografia da Pontifícia Universidade Católica do Rio de Janeiro (PUC-Rio) e Professor Associado da Universidade do Estado do Rio de Janeiro. Pesquisador 1D do Conselho Nacional de Desenvolvimento Científico e Tecnológico (CNPq).

Rua Marquês de São Vicente, 225 - Gávea, Rio de Janeiro - RJ, 22451-900

alvaro_ferreira@puc-rio.br

alvaro.ferreira.geo@gmail.com
\end{abstract}

Recebido para publicação em junho de 2018 Aprovado para publicação em setembro de 2018 